\title{
Percepções de enfermeiros sobre competências desenvolvidas nos cuidados pós-operatórios de transplante de fígado
}

\author{
Perceptions of nurses about the competences developed in postoperative care after a liver \\ transplant
}

\section{Como citar este artigo:}

Negreiros FDS, Pequeno AMC, Alencar CS, Carvalho GSO, Moreira TR. Perceptions of nurses about the competences developed in postoperative care after a liver transplant. Rev Rene. 2020;21:e41876. DOI: https://doi.org/10.15253/2175-6783.20202141876

(D) Francisca Diana da Silva Negreiros ${ }^{1}$
(D) Alice Maria Correia Pequeno ${ }^{2}$
(D) Carla Siebra de Alencar ${ }^{1}$
(D) Gemiliana Sombra de Oliveira Carvalho ${ }^{1}$
(D) Tatiana Rebouças Moreira ${ }^{1}$

${ }^{1}$ Universidade Federal do Ceará.

Fortaleza, CE, Brasil.

${ }^{2}$ Universidade Estadual do Ceará.

Fortaleza, CE, Brasil.

\section{Autor correspondente:}

Francisca Diana da Silva Negreiros

Rua Capitão Francisco Pedro, 1290, Rodolfo Teófilo

Hospital Universitário Walter Cantídio, Universidade

Federal do Ceará. CEP: 60430-370. Fortaleza, CE, Brasil.

E-mail: negreiros.diana@gmail.com

\begin{abstract}
RESUMO
Objetivo: desvelar percepções de enfermeiros acerca das competências desenvolvidas no pós-operatório imediato do transplante de fígado. Métodos: pesquisa qualitativa. Dados coletados por meio de entrevista semiestruturada e observação sistemática não participante, com oito enfermeiros da unidade de pós-operatório imediato de transplante de fígado de um hospital de referência. Para explanação dos resultados, utilizou-se a técnica de Análise de Conteúdo. Resultados: o conteúdo obtido a partir das entrevistas foi sistematizado em três eixos temáticos: preparo da Unidade de Terapia Intensiva pós-operatória para admissão do receptor de fígado; atuação de enfermeiros na internação do receptor de fígado em Unidade de Terapia Intensiva pós-operatória; atividades exercidas no âmbito gerencial, ensino e pesquisa. Conclusão: aponta-se que as competências desenvolvidas pelos enfermeiros ocorrem de forma direcionada e individualizada, envolvendo, de modo integrado, as dimensões administrativas, organizacionais, gerenciais, assistenciais e de ensino-pesquisa.

Descritores: Cuidados de Enfermagem; Competência Profissional; Cuidados Pós-Operatórios; Transplante de Fígado.
\end{abstract}

\begin{abstract}
Objective: discovering the perceptions of nurses concerning the competences developed in liver transplant postoperative care. Methods: qualitative research. Data were collected through a semi-structured interview and systematic nonparticipative observation, with eight nurses from the unit that received patients immediately after liver transplants. To explain the results, the Content Analysis technique was used. Results: the content found in the interviews was systematized in three thematic axes: preparing the postoperative Intensive Care Unit to receive the liver transplant receptor; actions of nurses concerning the liver transplant receptor in the postoperative Intensive Care Unit; activities related to administration, teaching, and research. Conclusion: the competences developed by the nurses are directed and individualized, involving, in an integrated whole, the administrative, organizational, managerial, healthcare-related, and teaching-research dimensions.

Descriptors: Nursing Care; Professional Competence; Postoperative Care; Liver Transplantation.
\end{abstract}




\section{Introdução}

No contexto da insuficiência hepática em estágio terminal, condição clínica grave que, em geral, acomete pessoas com doença hepática aguda ou crônica, o transplante de fígado é o método recomendado que demanda da equipe assistencial o desenvolvimento de competências específicas e consequentemente avanço terapêutico consistente, com impacto positivo na mudança e qualidade de vida ${ }^{(1)}$. Nessa conjuntura, informa-se que o Brasil tem se destacado na área de transplantes no contexto global, ocupando segundo lugar em números absolutos de transplantes de fígado no mundo. Em 2018, foram realizados 2.182 transplantes de fígado no país ${ }^{(2)}$.

0 transplante de fígado requer que profissionais desenvolvam competências qualificadas para cumprimento seguro das atividades que envolvem essa prática, uma vez que o transplante de órgãos, em particular o de fígado, constitui procedimento complexo e específico que necessita de completa infraestrutura e equipe multiprofissional especializada no desempenho de atribuições e assistência a pacientes gravemente enfermos ${ }^{(3)}$. Vale esclarecer que competência é a capacidade de o enfermeiro exercer ações amparadas em conhecimentos acumulados que contemplem conteúdos gerais e específicos relacionados às habilidades e atitudes que incorporem valores profissional e social às atividades, diferenciando-o nas circunstâncias em que trabalha ${ }^{(4)}$.

Nesse cenário, enfermeiros, como participantes da equipe multidisciplinar, atuam em todo processo, ou seja, desde seguimento ambulatorial até o pré, trans e pós-operatório do transplante de fígado, sendo fundamental para o cuidado de enfermagem seguro e distintivo. Em especial, o pós-operatório imediato demanda dos profissionais, em particular enfermeiros, a atuação intensa, com atitudes e habilidades próprias, pois é, nesse momento, que o receptor está mais suscetível às instabilidades hemodinâmicas, necessitando de intervenções clínicas e/ou cirúrgicas de forma rápida e eficiente ${ }^{(5)}$.
Assim, o planejamento de cuidado de enfermagem aos pacientes receptores de fígado visa avaliar, detectar, antecipar e intervir nas potenciais complicações pós-cirúrgicas, bem como complicações técnicas decorrentes do ato cirúrgico, da resposta imunológica do receptor e do regime de imunossupressã $0^{(3)}$. Diante do exposto e a fim de contribuir para assistência de enfermeiros e melhor qualidade do cuidado, questionou-se: como os enfermeiros percebem suas competências desenvolvidas no pós-operatório imediato de transplante de fígado?

Nessa compreensão, buscou-se desvelar percepções de enfermeiros acerca das competências desenvolvidas no pós-operatório imediato do transplante de fígado.

\section{Métodos}

Pesquisa qualitativa que utilizou a Análise de Conteúdo como referencial teórico-metodológico ${ }^{(6)}$. A investigação foi desenvolvida em Unidade de Terapia Intensiva pós-operatória do Hospital Universitário Walter Cantídio, da Universidade Federal do Ceará, instituição referência regional e nacional em transplantes de fígado.

O serviço contemplava na escala de trabalho um total de oito enfermeiros. Os critérios de inclusão foram pertencer ao serviço há pelo menos dois anos, pois considera-se que o desenvolvimento das competências necessárias à prestação de assistência no processo de transplante é favorecido durante esse período. Excluíram-se os profissionais que estavam substituindo temporariamente o enfermeiro por motivo de férias ou licença do mesmo e/ou aqueles que estavam ausentes, no período da coleta, por motivo pessoal ou licença médica. Aponta-se que não houve exclusão.

Após aplicação dos critérios de elegibilidade, todos os enfermeiros atenderam aos critérios de inclusão. Então, eles foram convidados a participar da pesquisa e não houve recusa. Portanto, participaram do estudo oito enfermeiros. 
A coleta de dados foi realizada em agosto de 2015. Realizaram-se entrevistas semiestruturadas e observação sistemática não participante. Os participantes foram informados sobre o processo da coleta de dados, sendo o dia, horário e local combinados conforme conveniência de cada profissional. Salienta-se que os subsídios sobre a coleta de dados constavam no Termo de Consentimento Livre e Esclarecido.

Para as entrevistas, utilizaram-se o roteiro e aparelho de gravação de voz digital, sendo os registros realizados após autorização prévia dos participantes e em sala reservada da Unidade de Terapia Intensiva, com duração média de 40 minutos, posteriormente, transcritos na íntegra pela pesquisadora.

0 roteiro guia da entrevista, elaborado pelo pesquisador, continha além da pergunta norteadora os seguintes dados: sexo, cor, religião, estado civil, idade, titulação, tempo de graduação, tempo que exerciam a profissão, tempo de atuação na área do transplante hepático, vínculos empregatícios e renda familiar. Salienta-se que teste piloto do roteiro foi realizado com três profissionais enfermeiros experientes na área de transplante hepático a fim de observar possíveis dificuldades para aplicabilidade deste, e as sugestões foram consideradas. Enfatiza-se que esses profissionais não participaram da pesquisa.

Nas observações, usou-se diário de campo, sendo realizadas pelo próprio pesquisador em diferentes períodos da semana, de segunda-feira a domingo, de manhã, tarde e/ou noite, em conformidade com as solicitações dos participantes. Dessa forma, todos os enfermeiros foram observados no exercício de suas atividades em serviço, totalizando, em média, 132 horas de observação.

0 tratamento dos dados obtidos foi submetido à Análise de Conteúdo ${ }^{(6)}$ após transcrição das entrevistas na íntegra, sendo que a organização do material transcrito foi realizada na etapa de pré-análise para definir as categorias e classificar as falas dos participantes; em seguida, as falas dos enfermeiros foram interpretadas e emergiram três categorias, as quais são apresentadas nos resultados.
Pesquisa aprovada pelo Comitê de Ética em Pesquisa do Hospital Universitário Walter Cantídio, da Universidade Federal do Ceará, com parecer no 646.428, a qual seguiu os princípios éticos preconizados pela Resolução 466/12, que regulamenta diretrizes e normas de pesquisas com seres humanos. A representação dos nomes dos participantes foi expressa pelo número, conforme ordem da entrevista, seguido pela letra $\mathrm{E}$, de Enfermagem (1E, 2E,..., 8E), garantindo, dessa forma, sigilo e anonimato destes durante o processo de pesquisa.

\section{Resultados}

A pesquisa contou com a participação de oito enfermeiros, destes a maioria era do sexo feminino, 7 (87,5\%), parda, 7 (87,5\%), católica, 8 (100\%), e casada, $5(62,5 \%)$. Idade média de 41 anos, variando entre 31 e 60 anos. Quanto à titulação, $5(62,5 \%)$ eram mestres e $3(37,5 \%)$ especialistas, destes $2(25,0 \%)$ tinham especialização em terapia intensiva e $1(12,5 \%)$ em gestão hospitalar. 0 tempo médio de formação foi de 20 anos. Exerciam a profissão e trabalhavam na área de transplante, em média, há sete anos. Com relação à situação trabalhista, 5 (62,5\%) declararam possuir dois vínculos empregatícios e os demais, 3 $(37,5 \%)$, tinham um emprego; e a renda familiar foi de 6 a 20 salários mínimos.

Das falas dos participantes emergiram três categorias temáticas: 1) Preparo da Unidade de Terapia Intensiva pós-operatória para admissão do receptor de fígado; 2) Atuação de enfermeiros na internação do receptor de fígado em Unidade de Terapia Intensiva pós-operatória; 3) Atividades exercidas no âmbito gerencial, ensino e pesquisa.

\section{Preparo da Unidade de Terapia Intensiva pós- operatória para admissão do receptor de fígado}

Após finalizar o procedimento de transplante, obrigatoriamente, o receptor é transferido da sala cirúrgica para Unidade de Terapia Intensiva pós-ope- 
ratória, onde permanecerá internado até restabelecimento dos padrões hemodinâmicos.

A partir do momento da confirmação do transplante, são disparadas ações do enfermeiro na organização do ambiente para propiciar segurança na ocasião da admissão do receptor na unidade. Nas falas dos enfermeiros, revelou-se preocupação em relação a recursos humanos, materiais médico-hospitalares, disponibilização de equipamentos e providências com o médico de exames e prescrição de medicamentos: Logo que o transplante é confirmado, o primeiro passo é montar o leito com todo o recurso de respirador, bomba de infusão, glicosímetro, soro, seringas, agulhas, sondas, dentre outros materiais iniciais que ele vai precisar e, além disso, testamos todos equipamentos para não ter erros (7E). Depois que preparamos o leito com todos os materiais, vamos ver a equipe, escalar o enfermeiro e o técnico de enfermagem que ficará responsável em receber o paciente (5E). Além de preparar a unidade, o enfermeiro pega os dados do receptor no centro cirúrgico. Então, repassamos as informações para o médico e ele vai efetuar o protocolo clínico do transplante para quando o receptor chegar, já ter a sua prescrição, solicitação dos exames laboratoriais e de imagens. Tudo para agilizar na hora da admissão (8E).

Para reduzir as complicações do pós-transplante, a equipe médica e de enfermagem oferecia, prontamente, cuidados efetivos e seguros na admissão do receptor na Unidade de Terapia Intensiva pós-operatória, como expressaram as falas a seguir: 0 enfermeiro, juntamente com o técnico de enfermagem, recebe o paciente advindo do centro cirúrgico. Na ocasião, é posicionado o respirador, realizada a monitorização cardíaca, da pressão arterial média e da venosa central. Observamos a infusão dos soros e drenagem das sondas (3E). Nas primeiras 24 horas de admissão [Unidade de Terapia Intensiva pós-operatória], os sinais vitais e o balanço hídrico são registrados de 1/1hora. São administradas as medicações prescritas, como vitamina Ke antibióticos... (6E).

Os entrevistados demonstraram apreensão quanto à escolha do leito do paciente para evitar a infecção cruzada com outros internados, visto que os indivíduos imunossuprimidos são mais suscetíveis às infecções parasitárias, e estes requerem maiores cuidados na prevenção e no controle da infecção: Sempre colocamos o recém-receptor em leito isolado, longe de contaminação, pois ele é imunossuprimido (2E). Um dos cuidados de enfermagem é o controle da infecção porque esse paciente vai começar a fazer o imunossupressor que é o tacrolimus, a hidrocortisona, e terá queda na imunidade. Então, ele já vem com isolamento reverso (1E).

\section{Atuação de enfermeiros na internação do receptor de fígado em Unidade de Terapia Intensiva pós- -operatória}

No pós-operatório, a avaliação, a monitorização intensiva e o acompanhamento clínico constante do paciente são importantes devido à instabilidade hemodinâmica após o transplante. A equipe de enfermagem é responsável por esses cuidados, por estar mais tempo com o paciente, conforme evidenciado na fala: Em todo período de internação, o receptor tem assistência intensiva. Observamos constantemente os parâmetros vitais, função do enxerto e nível de consciência. Depois de transcorrer às 24 horas do transplante e o receptor apresentar estabilidade nos parâmetros metabólicos, passamos a mensurar de 2/2 horas os sinais vitais, volumes infudidos e drenados, mas, se houver alguma instabilidade, volta para 1/1 hora. Temos os protocolos clínicos que seguimos (3E).

Quanto à assistência direta ao paciente, os enfermeiros exercem ações peculiares, como demonstraramdo as falas: Têm atividades que só o enfermeiro faz, como a troca de curativos, retirada de dreno e catéteres, aspiração orotraqueal, dentre outras tarefas. $O$ enfermeiro costuma supervisionar os procedimentos realizados no paciente. Está sempre por perto (1E).

Nas percepções dos entrevistados, evidenciou-se que o receptor, ao evoluir hemodinamicamente estável, é conduzido para enfermaria; seguidamente, o enfermeiro solicita o leito na enfermaria, repassando o estado clínico do paciente e prestando informações aos familiares; posteriormente, organiza prontuário e exames, bem como materiais pessoais do paciente para serem encaminhados na ocasião da transferência: Quando o paciente recebe alta da Unidade de Terapia Intensiva, comunicamos ao enfermeiro da enfermaria, pedimos um leito e repassamos tudo sobre o estado geral do paciente. Isso ajuda o outro serviço a organizar a enfermaria para receber o receptor com maior segurança (1E). Na hora da transferência, ligo para família vir. Juntamente com o paciente, mandamos o prontuário, a pasta do transplante hepático, a prescrição médica, a medicação prescrita 
do dia e todos os pertences, como material de higiene (4E).

Na observação em campo, confirmou-se que o enfermeiro promovia ações de educação em saúde, por meio de orientações e esclarecimentos de dúvidas para receptor e familiares, visando estimulá-los e envolvê-los no processo de cuidar: A nossa assistência inclui não apenas o paciente, como também os cuidadores ou família, pois sabemos que temos o papel de educadores. Aqui, toda a equipe provê informações mais claras possíveis, possibilitando maior entrosamento entre eles e a equipe (5E). Devido ao rebaixamento da consciência causado pela encefalopatia, temos que conversar com os familiares, orientando-os sobre os cuidados com os parentes, relacionados aos imunossupressores, riscos de infecções e rejeição do enxerto, dentre outros assuntos (2E).

\section{Atividades exercidas no âmbito gerencial, ensino e pesquisa}

As falas dos enfermeiros participantes também apontaram atividades complementares por eles realizadas, as quais envolvem componentes gerenciais, de ensino e pesquisa. Em relação ao gerencial, compete ao enfermeiro realizar ações administrativas e promover a integração do paciente com o corpo assistencial, que compreende as categorias de médico, psicólogo, assistente social, fisioterapeuta, dentre outros profissionais. Dessa forma, possibilita garantir o cuidado efetivo, de modo a atender às demandas dos pacientes e respectivos familiares, promovendo interfaces entre o cuidado individual e holístico: Nosso trabalho é intenso, estamos em ação direta com o paciente e/ou gerenciando o serviço. A parte do gerenciamento tem muita burocracia, escalas de funcionários, planilhas, relatórios e outros documentos que temos que preencher. Ainda, somos o elo entre a equipe multiprofissional com o paciente e família (5E). Ao perceber que o paciente está deprimido, solicitamos o psicólogo. Também pedimos à assistente social para resolver alguma pendência da família. Quando há intercorrência clínica, chamamos o médico e, se for caso de cirurgia, acionamos os cirurgiões. O serviço é muito integrado e eficiente (7E).

Percebeu-se que os enfermeiros desempenhavam também a função de ensino e pesquisa, uma vez que se figuravam como facilitadores de aprendizado para estudantes ou pessoas que estavam interessadas no processo de transplante e, ainda, participavam de eventos científicos, promoviam treinamentos e estavam em constante capacitação profissional: Como trabalhamos em hospital escola, sempre recebemos alunos e/ou profissionais de outras instituições que buscam aprender sobre transplante de fígado. E, para acolhermos essa população acadêmica, temos que também buscar capacitações (8E). Toda a equipe procura participar de congressos e desenvolver pesquisas juntamente com os alunos, pois isso nos ajuda a crescer como profissional e realizar a prática com maior segurança. O ensino e a pesquisa fazem parte das funções, não somente do enfermeiro, como dos demais colegas de trabalho (6E).

Diante das falas, evidenciou-se que enfermeiros constituem elementos-chave da equipe multiprofissional. A atuação desses respectivos profissionais proporciona trabalho interdisciplinar, como também promove o estabelecimento de vínculos, a corresponsabilidade entre a equipe, os receptores e familiares visando à preservação da saúde de maneira ampliada. Ainda, esse profissional participa de processos de educação permanente, quando busca o autoconhecimento, ao participar de capacitações, proporcionando treinamentos em serviço e acompanhamento de graduandos e residentes, no incremento do ensino e do aprendizado, baseados em evidências científicas.

\section{Discussão}

A quantitade restrita de participantes e a coleta de dados em único serviço hospitalar foram consideradas limitações do estudo, não sendo possível, dessa forma, generalizar os dados. Futuras investigações com maior quantitativo amostral e delineamentos metodológicos mais robustos são potenciais para dar seguimento aos achados desta investigação, possibilitando a divulgação de novas e diferentes competências dos enfermeiros na área do transplante hepático.

O presente estudo contribui para a notoriedade e valorização do profissional enfermeiro, visto que o mesmo exerce diversas funções com o objetivo de oferecer uma assistência de qualidade e holística para o paciente. Além disso, a pesquisa inovou ao dar ênfase 
à percepção do enfermeiro sobre sua própria atuação no campo do transplante hepático.

Os achados desta investigação revelaram que o enfermeiro é incumbido de tarefas fundamentais para o sucesso do transplante, as quais envolvem as dimensões assistencial e gerencial, bem como ensino e pesquisa. A partir dessa ótica de atuação do enfermeiro, pesquisa quantitativa, com 505 egressos da Escola de Enfermagem da Universidade de São Paulo, constatou que a maioria estava inserida na área assistencial $(66,0 \%)$, administrativa $(15,0 \%)$ e educacional $(12,0 \%)^{(7)}$. No que tange à gestão, revisão integrativa apontou que a ação gerencial de enfermeiros, voltada para atividades administrativo-burocráticas, era articulada insatisfatoriamente ao assistencial ${ }^{(8)}$. Isso contradiz os resultados deste trabalho, que sinalizou a conciliação entre as atividades burocráticas e assistenciais de enfermeiros.

Pesquisa qualitativa, também realizada no Ceará, evidenciou que enfermeiros são responsáveis pela admissão de pacientes na Unidade de Terapia Intensiva, no pós-operatório imediato do transplante, além de providenciar a organização dos recursos humanos, físicos e materiais. Ademais, devem possuir conduta autônoma e efetiva no planejamento, na realização e no plano assistencial do paciente receptor ${ }^{(9)}$.

Profissionais de saúde que assistem pacientes, em especial os enfermeiros, são imprescindíveis para evitar erros, impedir decisões errôneas, bem como assumir o papel de liderança e promover estratégias para assegurar a qualidade do cuidado ${ }^{(10)}$. Ademais, a equipe de enfermagem, no pós-operatório, deve avaliar a função cardiorrespiratória, saturação de oxigênio, nível de consciência, presença de dor, condições do curativo. É importante manter, nessa fase, a volemia, o suporte nutricional, a antibioticoterapia, avaliar exames, ou seja, monitorar o paciente de forma inten$\operatorname{siva}^{(3)}$.

Análise retrospectiva à documentação de pós-transplante de fígado revelou que enfermeiros registravam aspectos centrados na condição de ser receptor com o paciente que faz uso de imunossupressores e que a suscetibilidade à infecção foi identificada em $60,3 \%$ dos registros dos enfermeiros que mantiveram contato com estes pacientes, portanto, vê-se a necessidade de implementar intervenções sobre prevenção de complicações e controle da infecção. Ainda, relatou-se que a infecção foi uma das principais causas de morbimortalidade após o transplante de fígado ${ }^{(11)}$.

A participação ativa dos profissionais na prevenção e no controle de infecções é estratégia-chave nos programas de segurança dos pacientes nas organizações de saúde ${ }^{(9)}$. A partir desse entendimento, os entrevistados mencionaram o cuidado redobrado na vigilância da infecção devido ao uso de imunossupressores, acarretando risco de infecção.

Ainda no que se refere à assistência de enfermagem, no contexo do pós-operatório de transplante hepático, investigação apontou que os eventos neurológicos, as hemorragias, alterações cardiopulmonares, hematológicas, vasculares, biliares, infecções e a rejeição aguda do enxerto são as complicações mais prevalentes desse período, enfatizando a importância do cuidado intensivo de enfermagem com a monitorização sistemática do paciente, objetivando a prevenção de tais intercorrências ${ }^{(12)}$.

Observou-se que os participantes exerciam suas atividades com empatia, diálogo e escuta. Dessa forma, evidencia-se a relevância do vínculo entre o profissional e o paciente, sendo denominada de trabalhos vivos, colaborando para o desenvolvimento de percepção crítica, questionadora e transformadora do paciente ${ }^{(13)}$. 0 diálogo e a escuta são comparáveis com o tratamento medicamentoso ${ }^{(14)}$.

Por meio do falar e ouvir, os entrevistados exerciam ações de educação em saúde fornecendo orientações aos receptores e familiares. Investigação demonstrou que para a família da pessoa em tratamento crítico, em unidade de cuidados intensivos, a interação com a equipe de saúde revestiu-se de significado pela possibilidade de transmitir medos e preocupações e, simultaneamente, a partilha de conhecimento ${ }^{(15)}$.

Considera-se que o enfermeiro exerce um papel de fundamental importância no acompanhamento 
dos pacientes de transplante de fígado, podendo auxiliar essas pessoas no enfrentamento de mudanças, de modo a prestar cuidados individualizados, além de oferecer suporte às necessidades da família e do paciente. Os enfermeiros também podem contribuir na educação em saúde dos transplantados oferencendo apoio para o autocuidado e informações apropriadas para que a família possa colaborar na sua recuperação e reintegrá-los à sociedade ${ }^{(16)}$.

Ainda, investigação revelou que a prática da educação em saúde pelo enfermeiro, sobre as mudanças no estilo de vida, no pós-operatório imediato como a realização regular de atividade física, é essencial para promover a implementação de hábitos pelo paciente, o que impacta positivamente nos desfechos do transplante. A gestão em enfermagem deve fazer uso do planejamento para programação e implementação de atividades educativas ${ }^{(17)}$.

No contexto da educação compartilhada entre receptores e familiares, enfermeiros planejam intervenções centradas em orientações específicas, como gestão dos regimes terapêutico e medicamentoso, hábitos de exercício e repouso, dieta, prevenção de complicações, tratamentos, sinais de infeção e atividade sexual $^{(11)}$, objetivando maior adesão ao tratamento e empoderamento para o autocuidado.

Ademais, indica-se a importância da educação em saúde para promoção do cuidado seguro e da motivação de pacientes e familiares quanto à nova condição, fornecendo subsídios para empoderamento de indivíduos e familiares, com vistas à mudança efetiva de comportamento e adesão ao tratamento, para controle de comorbidades e fatores de risco, bem como imunossupressão adequada, possibilitando viabilidade do enxerto em longo prazo e prevenindo complicações ${ }^{(17)}$. Ainda, as práticas de educação em saúde proporcionam conhecimentos desde o esclarecimento de dúvidas relacionadas à clínica da doença até os cuidados com a nutrição, higiene e importância da continuidade do tratamento ${ }^{(18)}$.

A educação do cliente de transplante é um processo contínuo, devendo assistir usuários e familiares.
Estudo no Irã evidenciou que familiares de pacientes transplantados podem sofrer traumas psicológicos. Nesse sentido, recomenda-se aos membros da equipe de saúde, especialmente os enfermeiros, que forneçam às famílias as informações necessárias sobre o curso da doença e o processo de tratamento, para reduzir a ansiedade das famílias. Para isso, os enfermeiros devem ter níveis aceitáveis de compreensão e de conhecimento sobre as necessidades das famílias de pacientes transplantados para tomar as melhores medidas e atender às suas necessidades ${ }^{(19)}$.

Acerca das práticas seguras de assistência ao receptor, destaca-se a colaboração interprofissional, aquela em que profissionais atuam de forma integrada compartilhando objetivos e colocando usuários na centralidade do processo ${ }^{(17)}$. Nessa linha, o trabalho integrado com as equipes interdisciplinares é essencial para o desempenho de processos com foco na qualidade aumentando a eficiência e a solução de problemas $^{(10)}$. Tal afirmação reforça as falas dos profissionais deste estudo, que expressaram a atuação imprescindível do trabalho em equipe multidisciplinar, no pós-operatório imediato, de paciente-receptor.

No que concerne ao ensino e à pesquisa, sublinha-se a valorização dos entrevistados na promoção e participação de eventos científicos e desenvolvimento de pesquisa, aprimorando a prática clínica embasada em evidências. Estudo dos Estados Unidos apontou que a maioria dos graduados em enfermagem e medicina tem pouca exposição clínica a pacientes com doença hepática crônica ou a pacientes pós-transplante. Portanto, são necessários programas de pós-graduação para treinar ainda mais a prática desses profissionais em áreas especializadas, como o transplante ${ }^{(20)}$. Pesquisa com abordagem qualitativa corroborou que o procedimento do transplante de fígado demanda que o profissional acompanhe as evoluções científicas e novas tecnologias. Para tanto, deve buscar continuamente capacitações e atualizações, bem como proporcionar o ensino-aprendizado para acadêmicos e profissionais, enfim, para todos que revelem interesse sobre as questões relacionadas ao transplante ${ }^{(9)}$. 


\section{Conclusão}

Aponta-se que as competências desenvolvidas pelos enfermeiros ocorrem de forma direcionada e individualizada, envolvendo, de modo integrado, as dimensões administrativas, organizacionais, gerenciais, assistenciais e de ensino-pesquisa.

\section{Colaborações}

Negreiros FDS, Pequeno AMC Alencar CS Carvalho GSO Moreira TR contribuíram na concepção e projeto, análise e interpretação dos dados, redação do artigo, revisão crítica relevante do conteúdo intelectual e aprovação final da versão a ser publicada.

\section{Referências}

1. Eiras FRC, Barbosa AP, Leão ER, Biancolino CA. Use of a severity indicator as a predictor of the use of hepatic transplantation resources. Rev Esc Enferm USP. 2016; 50(4):579-86. doi: http://dx.doi. org/10.1590/S0080-623420160000500006

2. Associação Brasileira de Transplantes de Órgãos. Dimensionamento dos transplantes no Brasil e em cada estado (2011-2018). Registros Bras Transpl [Internet]. 2018 [citado 2019 Mar 12]; XXIV(4):188. Disponível em: http://www.abto.org.br/ abtov03/Upload/file/RBT/2018/Lv_RBT-2018. pdf

3. Pereira WA. Manual de transplantes de órgãos e tecidos. Belo Horizonte: Coopmed; 2012.

4. Holanda FL, Marra CC, Cunha ICKO. Professional competency profile of nurses working in emergency services. Acta Paul Enferm. 2015; 28(4):308-14. doi: dx.doi.org/10.1590/1982-0194201500053

5. Negreiros FDS, Pequeno AMC, Alencar CS, Carvalho GSO, Chagas RR, Pinheiro YN, et al. Competências de enfermeiros no pós-operatório imediato de transplante hepático: concepção profissional. Investig Qual Saúde [Internet]. 2018 [citado 2019 ago 10];2:392-400. Disponível em: https:// proceedings.ciaiq.org/index.php/ciaiq2018/ article/view/1800/1753
6. Minayo MCS. O desafio do conhecimento: pesquisa qualitativa em saúde. São Paulo: Hucitec; 2013.

7. Püschel VAA, Costa D, Reis PP, Oliveira LB, Carbogim FC. Nurses in the labor market: professional insertion, competencies and skills. Rev Bras Enferm. 2017; 70(6):1220-6. doi: http:// dx.doi.org/10.1590/0034-7167-2016-0061

8. Mororó DDS, Enders BC, Lira ALBC, Silva CMB, Menezes RMP. Concept analysis of nursing care management in the hospital context. Acta Paul Enferm. 2017; 30(3):323-32. Disponível em: http:// dx.doi.org/10.1590/1982-0194201700043

9. Negreiros FDS, Pequeno AMC, Garcia JHP, Aguiar MIF, Moreira TR, Flor MJN. Multi-professional team's perception of nurses' competences in liver transplantations. Rev Bras Enferm. 2017; 70(2):242-8. doi: http://dx.doi. org/10.1590/0034-7167-2016-0223

10. Agência Nacional de Vigilância Sanitária. Assistência segura: uma reflexão teórica aplicada à prática [Internet]. 2017 [citado 2019 ago 10]. Disponível em: http://portal.anvisa. gov.br/documents/33852/3507912/Caderno+1+-+Assist \%C3\%AAncia+Segura+-+Uma+Reflex\%C3\%A3o+Te\%C3\%B3rica+Aplicada+\%C3\%A0+Pr\%C3\%A1tica/97881798-cea0-4974-9d9b-077528ea1573

11. Mota L, Bastos FS, Brito MAC. A pessoa submetida a transplante de fígado: terapêuticas de enfermagem no follow-up. Rev Enf Ref. 2018; serIV(16):19-28. doi: http://dx.doi.org/10.12707/RIV17086

12. Morais EN, Conrad D, Machado GC, Abreu MO, Matos EM, Cruz SAC. Postoperative complications of liver transplant: evidence for the optimization of nursing care. Rev Pesq Cuid Fundam Online. 2017; 9(4):999-1007. doi: http://dx.doi. org/10.9789/2175-5361.2017.v9i4.999-1007

13. Oliveira JSB, Suto CSS, Silva RS. Tecnologias leves como práticas de enfermagem na atenção básica. Rev Saúde Com [Internet]. 2016 [citado 2019 ago 10];12(3):613-21. Disponível em: http:// periodicos2.uesb.br/index.php/rsc/article/ view/425/344

14. Michelan VCA, Spiri WC. Perception of nursing workers humanization under intensive therapy. Rev Bras Enferm. 2018; 71(2):372-8. doi: http:// dx.doi.org/10.1590/0034-7167-2016-0485 
15. Mendes A. A interação enfermeiro-família na experiência vividade doença critica: o cuidado centrado na família. Investig Qual Saúde [Internet]. 2018 [citado 2019 ago 10];2:203-12. Disponível em: https://proceedings.ciaiq.org/index.php/ ciaiq2018/article/view/1780/1733

16. Aguiar MIF, Alves NP, Braga VAB, Souza ÂMA, Araújo MÂM, Almeida PC. Psychosocial aspects of quality of life of hepatic transplant receivers. Texto Contexto Enferm. 2018; 27(2):e3730016. doi: dx. doi.org/10.1590/0104-070720180003730016

17. Pearson JA, Mangold K, Kosiorek HE, Montez M, Smith DM, Tyler BJ. Registered nurse intent to promote physical activity for hospitalised liver transplant recipients. J Nurs Manag. 2018; 26(4):442-8. doi: http://dx.doi.org/10.1111/ jonm.12561
18. Azevedo IC, Cassiano AN, Carvalho JBL, Ferreira Júnior MA. Nursing care for hematopoietic stem cell transplant recipients and their families. Rev Rene. 2017; 18(4):559-66. doi: https://dx.doi. org/10.15253/2175-6783.2017000400019

19. Divdar Z, Foroughameri G, Farokhzadian J, Sheikhbardsir H. Psychosocial needs of the families with hospitalized organ transplant patients in an educational hospital in Iran. Ther Apher Dial. 2019. doi: http://dx.doi.org/10.1111/17449987.13425

20. Chaney AJ, Yataco ML. The emerging role of nurse practitioners and physician assistants in liver transplantation. Liver Transpl. 2019; 25(7):11059. doi: http://dx.doi.org/10.1002/lt.25474

\section{(cc) BY}

Este é um artigo de acesso aberto distribuído sob os termos da Licença Creative Commons 